\title{
Three-Dimensional Arrangement of Genes Involved in Lipid Metabolism in Nuclei of Porcine Adipocytes and Fibroblasts in Relation to Their Transcription Level
}

\author{
B. Kociucka J.Cieslak I. Szczerbal \\ Department of Genetics and Animal Breeding, Poznan University of Life Sciences, Poznan, Poland
}

\section{Key Words}

Adipocytes $\cdot$ Chromosome territories $\cdot$ Fibroblasts $\cdot 3 D$

fluorescence in situ hybridization - Gene positioning •

Lipogenic genes $\cdot$ Nuclear organization · Pig · Transcription

\begin{abstract}
The 3-dimensional arrangement of chromosomes and genes within a nuclear space is considered to represent the level of transcriptional regulation. Understanding how the nuclear architecture of adipocyte cells contributes to gene expression has become the subject of great interest in the context of obesity research. In this study we investigated nuclear positioning of 3 gene loci involved in lipid metabolism in the pig (Sus scrofa, SSC) which is considered as an important animal model for obesity in humans. We found that the position of the $S C D$ gene in the 3-dimensional space of the cell nucleus is not correlated with transcriptional activity. The gene locus as well as chromosome territory SSC14 occupied the same peripheral location in adipocyte and fibroblast cells, in spite of the fact that their transcription level differs significantly between both cell types. For the 2 other investigated genes, i.e. ACACA and SREBF1 and their chromosome territory (SSC12), slightly different nuclear locations were found. They occupied intermediate nuclear positions in fi-
\end{abstract}

broblast nuclei, while in adipocytes they were positioned in the nuclear interior. The more internal location of these genes corresponds to increased transcription levels in fat cells. Our results confirm the non-random position of genes and chromosome territories in nuclei of adult porcine cells and indicate that relationship between transcription activity and gene positioning exists only for some but not all genes.

Copyright $\odot 2012$ S. Karger AG, Basel

In recent years the 3-dimensional (3D) organization of the genome in a cell nucleus has become the focus of increasing interest. It is generally accepted that chromosomes and genes are positioned nonrandomly in interphase nuclei of mammalian cells [for review, see Meaburn and Misteli, 2007; Takizawa et al., 2008a; Cremer and Cremer, 2010; Ferrai et al., 2010]. Chromosome territories (CTs) are radially arranged and occupy preferential locations towards either the nuclear periphery or the nuclear interior, depending on their size or gene density [Croft et al., 1999; Boyle et al., 2001; Bolzer et al., 2005]. Moreover, transcriptional activity, replication timing or GC content have also been considered as other parameters influencing the organization of CTs and subchromosomal regions in the nucleus [Goetze et al., 2007; Grasser

\section{KARGER}

Fax +4161306 1234

E-Mail karger@karger.ch

www.karger.com
(C) 2012 S. Karger AG, Basel

$1424-8581 / 12 / 1364-0295 \$ 38.00 / 0$

Accessible online at:

www.karger.com/cgr
Izabela Szczerbal

Department of Genetics and Animal Breeding

Poznan University of Life Sciences

Wolynska 33, PL-60-637 Poznan (Poland)

Tel. +48 61846 6115, E-Mail izabel@jay.au.poznan.pl 
et al., 2008; Hepperger et al., 2008]. Chromosome arrangement is evolutionarily conserved and appears to be cell- and tissue-specific [Tanabe et al., 2002; Parada et al., 2004; Neusser et al., 2007].

It is believed that the spatial organization of chromosomes and gene loci within the nucleus has a regulatory function on transcription activity. The nuclear periphery is considered as a transcriptionally less active region, enriched in repressed chromatin, whereas the nuclear interior is a transcriptionally active part of the nucleus. It has been demonstrated that specific genome regions associated with nuclear lamina and lamina-associated domains represent a repressive chromatin environment [Guelen et al., 2008]. Experiments with targeting of genes to the nuclear periphery have revealed transcriptional repression of some genes, but not others [Finlan et al., 2008; Reddy et al., 2008]. Therefore, location at the nuclear periphery is not always associated with gene repression. On the other hand, analyses of nuclear positioning of the monoallelically expressed GFAP gene have shown that the active allele was more internally localized than the non-expressed allele [Takizawa et al., 2008b]. However, there are some exceptions from this generally accepted model of nuclear architecture of eukaryotic cells. It has been found that the nuclear architecture of nocturnal rod photoreceptor cells is inverted, with heterochromatin located in the nuclear interior and euchromatin in the nuclear periphery [Solovei et al., 2009]. Evidence for a role of the nuclear architecture in the regulation of cellular function has come from observations of repositioning of genes in the nuclear space, which corresponds with their transcriptional status. It was observed that some genes located at the nuclear periphery and being in an inactive state are relocalized to the nuclear interior upon induction [Kosak et al., 2002; Kim et al., 2004; Ragoczy et al., 2006; Williams et al., 2006; Szczerbal et al., 2009]. Repositioning of loci away from their chromosome territory can occur by formation of chromatin loops [Volpi et al., 2000; Chambeyron and Bickmore, 2004; Williams et al., 2006; Szczerbal et al., 2009; Ferrai et al., 2010], but the looping is not always linked with the regulation of gene expression since there are examples of gene looping without changes in the expression level [Morey et al., 2009]. Gene relocation is thought to be a mechanism allowing access of individual genes to appropriate nuclear subcompartments and association with specific nuclear domains [Egecioglu and Brickner, 2011]. Interaction of genes with the nuclear lamina has been reported as a mechanism for gene silencing [Finlan et al., 2008; Reddy et al., 2008; Peric-Hupkes et al., 2010], whereas associa- tion with transcription factories or nuclear speckles is considered as a mechanism for promoting transcription [Osborne et al., 2004; Xu and Cook, 2008; Szczerbal and Bridger, 2010].

Adipocyte biology has become a subject of great interest due to their role in the pathogenesis of obesity and other metabolic and cardiovascular disorders. Despite the fact that extensive studies have been carried out on the genetic background of obesity, only a small fraction of sequence variation which has functional significance has been identified. Thus, apart from genetic mechanisms involved in obesity development also epigenetic mechanisms should be considered. In spite of the importance of adipocytes, the knowledge on the nuclear architecture of fat cells is limited. To date, there is only 1 study focusing on the position of 2 chromosomes in human preadipocytes and adipocytes [Kuroda et al., 2004]. Recently, 3D arrangements of chromosomes and genes in interphase nuclei during porcine adipogenesis have been described [Szczerbal et al., 2009; Szczerbal and Bridger, 2010]. The pig (Sus scrofa, SSC) is considered a promising animal model for obesity research because of the similarities with human found at the physiological and genomic levels [Spurlock and Gabler, 2008]. Moreover, this species has chromosomes differing in size and morphology and possessing many conservative regions with human chromosomes. Thus, this species is also an attractive model for studies on the 3D nuclear organization of the genome.

The focus of this study was to determine the nuclear organization of genes in fully-developed adult pig cells. We selected 3 genes important for lipid metabolism. The SCD (stearoyl CoA desaturase) and ACACA (acetyl-CoA carboxylase alpha) genes encode key lipogenic enzymes. The SCD enzyme is involved in the biosynthesis of unsaturated fatty acids, while ACACA catalyses the first committed step in the biosynthesis of long-chain fatty acids by converting acetyl-CoA into malonyl-CoA. The third gene, SREBF1 (sterol regulatory element binding transcription factor 1), encodes the transcription factor involved in adipocyte differentiation as well as sterol biosynthesis. We have examined the nuclear position of these genes in interphase nuclei of mature adipocytes and compared their positions in fibroblast nuclei. These 2 cell types differed significantly in the transcription level of the studied genes. We hypothesized that differential gene expression profiles of the studied genes might reflect their differential positioning in the nuclear space in the 2 cell types with distinct functions. 


\section{Materials and Methods}

\section{Cell Culture}

Dermal tissue samples (collected from ear skin biopsies) were used to establish porcine fibroblast cell lines. The cell lines were grown in Dulbecco's modified Eagles medium (DMEM) supplemented with $15 \%(\mathrm{v} / \mathrm{v})$ fetal bovine serum and $1 \%(\mathrm{v} / \mathrm{v})$ penicillin/ streptomycin at $37^{\circ} \mathrm{C}$ in a humidified atmosphere containing $5 \%$ $\mathrm{CO}_{2}$. Cells were passaged 2-3 times per week. For 3D fluorescence in situ hybridization (FISH) analysis, fibroblasts were grown on glass slides to $80 \%$ confluency.

\section{Isolation of Porcine Adipocytes}

Porcine adipocytes were isolated according to the procedure described by Fernyhough et al. [2004] with minor modifications. Subcutaneous fat pads were collected from pigs at slaughter (3 months old, Landrace breed) and immediately transferred to sterile $37^{\circ} \mathrm{C}$ Hanks' balanced salt solution (HBSS) containing $1 \%(\mathrm{v} / \mathrm{v})$ penicillin/streptomycin. The adipocyte tissues were cut into small pieces and digested using collagenase solution $(0.25 \%$ collagenase (v/v), $5 \mathrm{~mm}$ glucose, $1.5 \%(\mathrm{v} / \mathrm{v}) \mathrm{BSA}$ in PBS) at $37^{\circ} \mathrm{C}$ for $1 \mathrm{~h}$. After enzymatic cell dispersal fat tissue was filtered through a sterile plastic mesh, and the filtrate was centrifuged for $10 \mathrm{~min}$ at $186 \mathrm{~g}$. The fatty layer, containing mature adipocytes, was collected, and the adipocytes were attached to poly-L-lysine-coated slides.

\section{DNA Probes}

Probes for the detection of studied genes were derived from the porcine BAC library (CHORI-242, http://bacpac.chori.org/ libraries.php). The ACACA gene was detected with clone $\mathrm{CH} 242$ 27L18, the SCD gene with CH242-80A3 and the SREBF1 gene with $\mathrm{CH} 242-409 \mathrm{P} 19$. Each clone was verified by PCR amplification directly from the bacterial suspension using gene-specific primers (primer sequences available on request). The BAC DNA was isolated by a standard alkaline lysis method and labeled by randompriming with biotin-16-dUTP (Roche). Porcine chromosome painting probes for SSC12 and SSC14, generated from flow-sorted chromosomes using DOP-PCR, were kindly provided by Prof. Malcolm A. Ferguson-Smith and Dr. Patricia O'Brien (Cambridge Resource Centre for Comparative Genomics, Cambridge University, UK). Primary DOP-PCR products were used as a source of template for the incorporation of biotin-16-dUTP (Roche) in a second round of DOP-PCR amplification.

\section{D Fluorescence in situ Hybridization}

Two-dimensional FISH was performed in order to confirm the specificity of the BAC probes. Porcine chromosome preparations were obtained from lymphocyte cultures and stained with the Qbanding technique prior to FISH. The FISH experiments were carried out according to Szczerbal et al. [2007]. Briefly, biotinlabeled BAC probes with an excess of porcine competitor DNA were denatured for $10 \mathrm{~min}$ at $70^{\circ} \mathrm{C}$, preannealed for $20 \mathrm{~min}$ at $37^{\circ} \mathrm{C}$, and applied onto denatured chromosome preparations. Hybridization was carried out overnight at $37^{\circ} \mathrm{C}$. Signal detection was performed using streptavidin $\mathrm{Cy} 3$ (Amersham) diluted at 1:200. Chromosomes were counterstained with 4',6-diamidino2-phenylindole (DAPI) in Vectashield medium (Vector Laboratories). The international nomenclature for pig chromosomes [Gustavsson et al., 1988] was used.

3D Nuclear Arrangement of Porcine

Genes in Adipocytes and Fibroblasts

\section{D Fluorescence in situ Hybridization}

Three-dimensional FISH was performed as described previously by Szczerbal et al. [2009]. In brief, fibroblasts grown directly on glass slides and adipocytes adherent to poly-L-lysine-coated slides were fixed in $4 \%$ paraformaldehyde in $1 \times$ PBS for $10 \mathrm{~min}$. The cells were then permeabilized with $0.5 \%$ Triton X-100 and $0.5 \%$ saponin in $1 \times$ PBS for $20 \mathrm{~min}$. The cells were then incubated in $20 \%$ glycerol, $1 \times$ PBS for at least $30 \mathrm{~min}$ before being snap-frozen in liquid nitrogen. The cells were repeatedly frozen and thawed 7 times. Before hybridization, cells were treated with $0.1 \mathrm{M} \mathrm{HCl}$ for $5 \mathrm{~min}$ at room temperature (RT) and a pepsin solution $(0.002 \%$ in $0.01 \mathrm{M}$ $\mathrm{HCl}$ ) for $5 \mathrm{~min}$ at $37^{\circ} \mathrm{C}$, followed by washing in PBS with $1 \mathrm{M} \mathrm{MgCl}_{2}$ and equilibration in $50 \%$ formamide, $2 \times$ SSC. Probes were denatured at $70^{\circ} \mathrm{C}$ for $10 \mathrm{~min}$ and then were preannealed at $37^{\circ} \mathrm{C}$ for 20 min. Nuclei were denatured at $76^{\circ} \mathrm{C}$ for $3 \mathrm{~min}$ in $70 \%$ formamide, $2 \times$ SSC followed by $50 \%$ formamide, $2 \times$ SSC for $1 \mathrm{~min}$. Hybridization was performed over 2 nights at $37^{\circ} \mathrm{C}$. Post-hybridization washes were performed for $3 \times 5 \mathrm{~min}$ in $50 \%$ formamide, $2 \times \mathrm{SSC}$ at $45^{\circ} \mathrm{C}$ and for $3 \times 5 \mathrm{~min}$ in $2 \times \mathrm{SSC}$ at $45^{\circ} \mathrm{C}$. The slides were then placed in $0.05 \%$ Tween $20,4 \times$ SSC at RT for $10 \mathrm{~min}$ and blocked in $3 \%$ BSA, $4 \times$ SSC at RT for $30 \mathrm{~min}$. Signal detection and nucleus counterstaining were performed as for 2D FISH.

\section{Microscopy and Image Analysis}

Cells were examined with a Nikon E600 Eclipse fluorescence microscope and a Zeiss LSM 510Meta confocal microscope. Images from a laser scanning microscope were taken through a Plan Apo oil immersion objective $100 \times / 1.4$ using Zeiss LSM 510 vs 3.2 SP1 software. Series of optical sections through 3D-preserved nuclei were collected with a $\mathrm{z}$-step of $0.3 \mu \mathrm{m}$ and a pixel size of 0.09 $\mu \mathrm{m}$ to obtain stacks of 8 -bit gray scale image $(1,024 \times 1,024$ pixels). Approximately, 100 nuclei for gene position and 50 for positioning of chromosome territories were analyzed. Object segmentations and measurements of the shortest distance from the center of hybridization spots (genes and chromosomes) to the nuclear border and to the center of the nucleus were taken using NEMO [Iannuccelli et al., 2010], developed from Smart 3D FISH graphical interface [Gué et al., 2005]. NEMO offers a function that automatically detects objects (genes and chromosome territories) in cells by the intensity of pixels above a globally set threshold. Depending on the type of detected objects (genes or chromosome territories) the global thresholds are computed differently. If necessary, the segmentation thresholds were adjusted manually to improve object detection [Iannuccelli et al., 2010; Solinhac et al., 2011]. To determine the radial position of studied genes the ratio of measurement distance was calculated $(R=$ distance from the FISH signal to the nucleus center by distance from the FISH signal to the nuclear border). Value $R<1.37$ was considered as nuclear interior, $1.37 \leq R \leq 4.45$ was considered as an intermediate position and $R>4.45$ was considered as nuclear periphery. Using NEMO graphical interface, the volumes of chromosome territories were also measured. Approximately 50 nuclei of fibroblasts and adipocytes were analyzed, and the volumes of chromosome territories were expressed as percentages of the total nuclear volume.

\section{Statistical Analysis}

Pairwise comparisons between the location of genes and chromosome territories in fibroblasts and adipocytes were performed using the nonparametric Mann-Whitney $U$ test. The $p$ values $<0.05$ were considered significant. 
Table 1. Real-time PCR amplification conditions for ACTB, ACACA, SCD and SREBF1 genes

\begin{tabular}{|c|c|c|c|c|}
\hline Primer sequence & $\begin{array}{l}\text { PCR product } \\
\text { length, bp }\end{array}$ & $\begin{array}{l}\text { Annealing tem- } \\
\text { perature, }{ }^{\circ} \mathrm{C}\end{array}$ & No. of cycles & $\begin{array}{l}\text { Source sequence } \\
\text { (GenBank) }\end{array}$ \\
\hline $\begin{array}{l}\text { ACTB-F: cccccgacaccagggcgtgat } \\
\text { ACTB-R: cggccagaggcgtacagggacag }\end{array}$ & 330 & 62 & 40 & AY550069 \\
\hline $\begin{array}{l}\text { ACACA-F: gcggatgggcggaatggtctc } \\
\text { ACACA-R: tgccagcctgtcgtcctcaat }\end{array}$ & 223 & 62 & 45 & EU168399 \\
\hline $\begin{array}{l}\text { SREBF1-F: gcgacggtgcctctggtagt } \\
\text { SREBF1-R: cgcaagacggcggattta }\end{array}$ & 218 & 55 & 45 & AF102873 \\
\hline
\end{tabular}

Quantitative Real-Time RT-PCR

Total RNA from adipocyte and fibroblast cell cultures was extracted with a GenElute Mammalian Total RNA Miniprep Kit (Sigma-Aldrich) according to the manufacturer's protocol. After isolation, $1 \mu \mathrm{g}$ of RNA was used as a template for complementary DNA (cDNA) synthesis. Relative transcription levels of ACACA, $S C D$ and SREBF1 in adipocytes and fibroblasts were measured (real-time PCR) in duplicate using SYBR Green (Roche) detection (LightCycler 2.0 system, Roche). The relative mRNA abundance was normalized to the beta-actin $(A C T B)$ reference gene. PCR primer pairs were designed using Primer3 software (http://frodo. wi.mit.edu/primer3/). Primer sequences and real-time amplification conditions for all investigated genes are shown in table 1.

\section{Results and Discussion}

In order to compare spatial arrangements of porcine genes in the nuclei of adipocytes and fibroblasts, we first selected 3 genes important for lipid metabolism. The 2D FISH technique was applied on metaphase spreads to establish chromosomal locations of the studied genes and confirm the specificity of BAC clones (fig. 1). The SCD gene was assigned to porcine chromosome $14 \mathrm{q} 27$, this localization being in agreement with a previous study by Ren et al. [2003]. Two other genes, i.e. ACACA and $S R E B F 1$, were localized in SSC12. The chromosomal location of SREBF1 was already shown earlier, mapping to SSC12q15 [Szczerbal and Chmurzynska, 2008], while $A C A C A$ was assigned to SSC12q12-q13. The location of $A C A C A$ is inconsistent with a previous mapping report [Calvo et al., 2000] in which the authors indicated the location in the p-arm of SSC12. Based on a comparative chromosome map of pig and human (https://www-lgc. toulouse.inra.fr/pig/compare/SSCHTML/SSC12S.HTM) as well as the NCBI Map Viewer (http://www.ncbi.nlm. nih.gov/projects/mapview/map_search.cgi?taxid=9823), where the location of the ACACA gene is also indicated as SSC12q, we concluded that our localization is correct.

Using 3D FISH and 3D image analyses we determined radial positioning of the studied genes in nuclei of adipocytes and fibroblasts (fig. 2; online supplementary fig. 1; see www.karger.com/doi/10.1159/000338255 for all online supplementary material). The SCD gene was located at the nuclear periphery in both adipocyte and fibroblast nuclei. The ACACA gene was found to have a different location in the studied cells - in fibroblast nuclei it occupied an intermediate position, since the signal was positioned between the nuclear periphery and the nuclear interior, while in adipocyte nuclei the gene signal was preferentially observed towards the nuclear interior. A similar situation was observed for the SREBF1 gene, which was located in an intermediate position in fibroblast nuclei and occupied the nuclear interior in adipocytes. Additionally, radial positioning of the chromosomes harboring the studied loci was determined in nuclei derived from fibroblasts and adipocytes (fig. 3, online suppl. fig. 2). We found that chromosome territories of SSC12 were positioned in an intermediate position in fibroblast nuclei and occupied the nuclear interior in adipocytes. Chromosome territories of SSC14 were located at the nuclear periphery in both cell types. Afterwards the relative transcriptional levels of the 3 studied genes ( $S C D$, $A C A C A$, SREBF1) were analyzed in fibroblast and adipocyte cells. We found that relative mRNA abundance of all the investigated genes is many times higher in adipocytes when compared to their relative transcription levels measured in fibroblasts (fig. 2).

Taken together, our study has shown that positioning of the SCD gene in the 3-dimensional space of the cell 

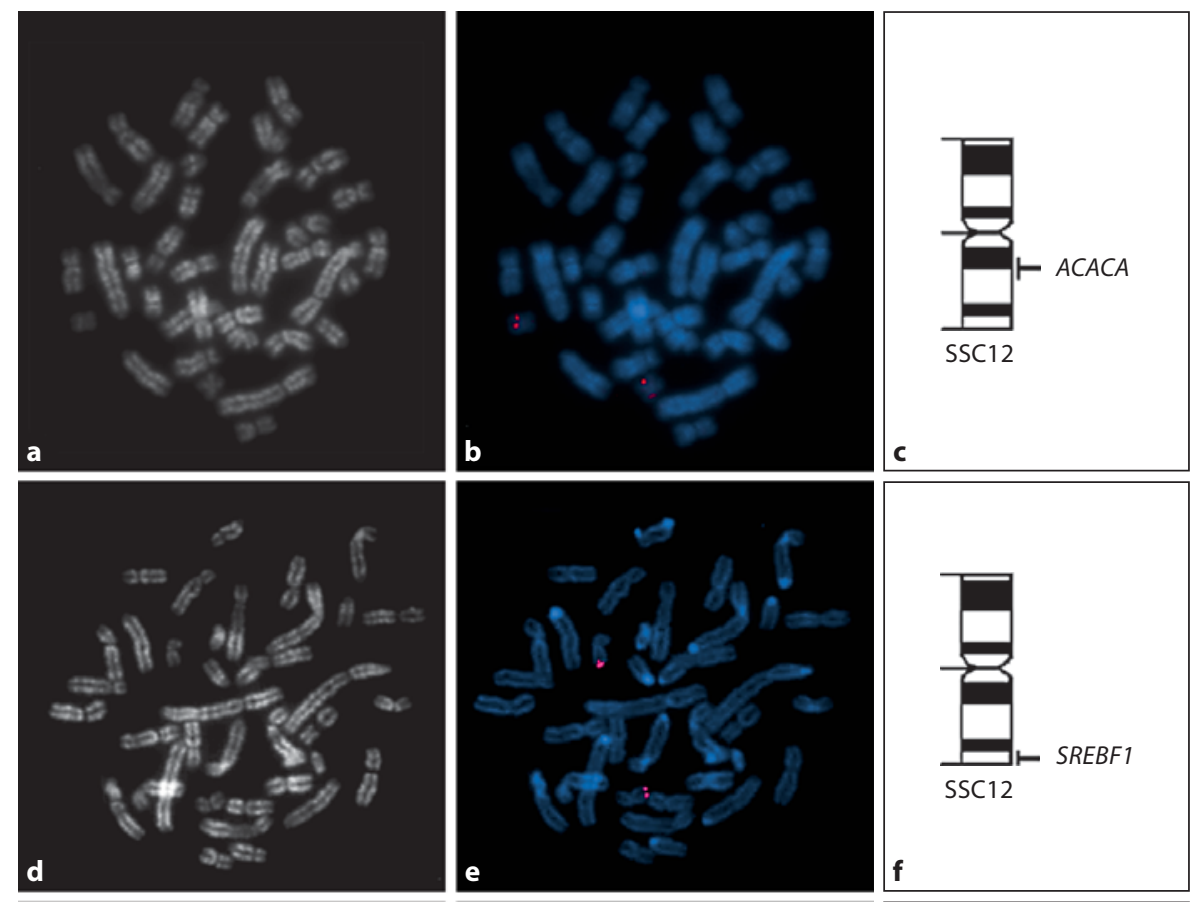

Fig. 1. Localization of $A C A C A, S R E B F 1$ and $S C D$ genes in pig chromosomes. a, d, $\mathbf{g}$ QFQ banding of metaphase spreads. $\mathbf{b}, \mathbf{e}$, h The same metaphase spreads after FISH with BAC probes specific for ACACA (b), $S R E B F 1$ (e) and $S C D$ (h). c, f, i Ideograms of SSC12 and SSC14 with indicated localizations of ACACA (c), SREBF1 (f) and $\operatorname{SCD}(\mathbf{i})$.
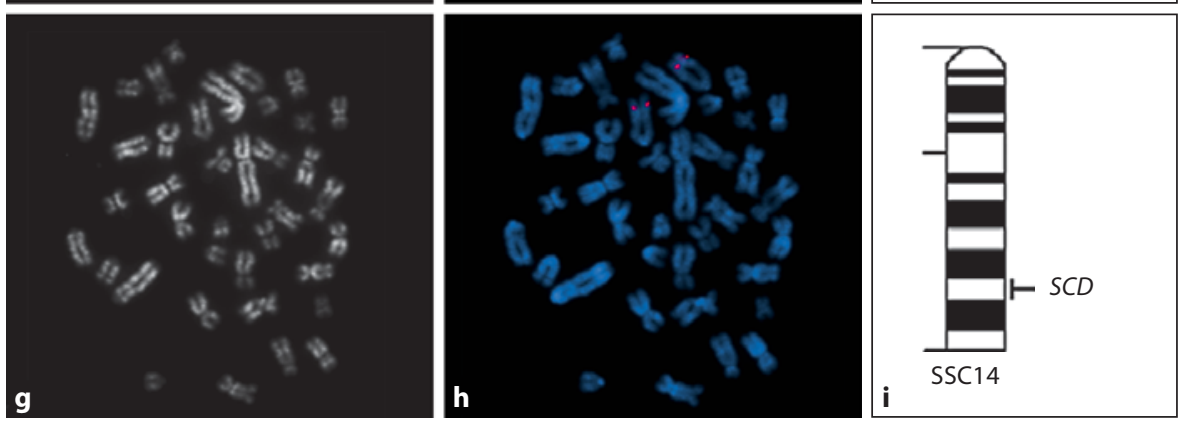

nucleus is not correlated with transcriptional activity the gene locus occupied the same peripheral location in adipocyte and fibroblast cells, despite the fact that its expression level differs significantly between both cell types. It seems that the nuclear location of the gene is determined by chromosome position, since chromosome SSC14 was preferentially observed on the nuclear edge. On the other hand, the 2 other genes, i.e. ACACA and $S R E B F 1$, and the chromosome carrying these loci (SSC12), changed the position from intermediate in fibroblast nuclei to a more internal location in adipocyte nuclei, and these changes corresponded with differences in expression levels. However, it may not be definitely concluded that the alteration in gene/chromosome positioning in the 2 cell types studied is a direct consequence of different transcriptional profiles.

In the present study, we observed a nonrandom arrangement of 2 porcine chromosomes in 2 cell types. The chromosome territories of SSC12 were located in an intermediate position in fibroblasts and at the nuclear interior in adipocyte cells. This localization indicated the cell type-specific positioning of chromosome territories in porcine cells. In our previous study, the position of SSC12 in porcine mesenchymal stem cells, preadipocytes and adipocytes during differentiation was reported as nuclear interior [Szczerbal et al., 2009]. The metacentric SSC12 is one of the smallest $(64 \mathrm{Mb})$ and a gene-rich $(20$ genes/ $\mathrm{Mb}$ ) porcine chromosome. Its human counterpart, HSA17, was also positioned in the nuclear interior in different human cells [Boyle et al., 2001; Heride et al., 2010]. The chromosome territories of SSC14 were located at the nuclear periphery. It is a relatively large $(154 \mathrm{Mb})$, but gene-poor ( 9 genes $/ \mathrm{Mb}$ ) porcine chromosome. A comparison of the position of SSC14 with human homologous chromosomes is more difficult; SSC14 consists of 6 conservative chromosomal regions with human chromosomes (HSA1, 

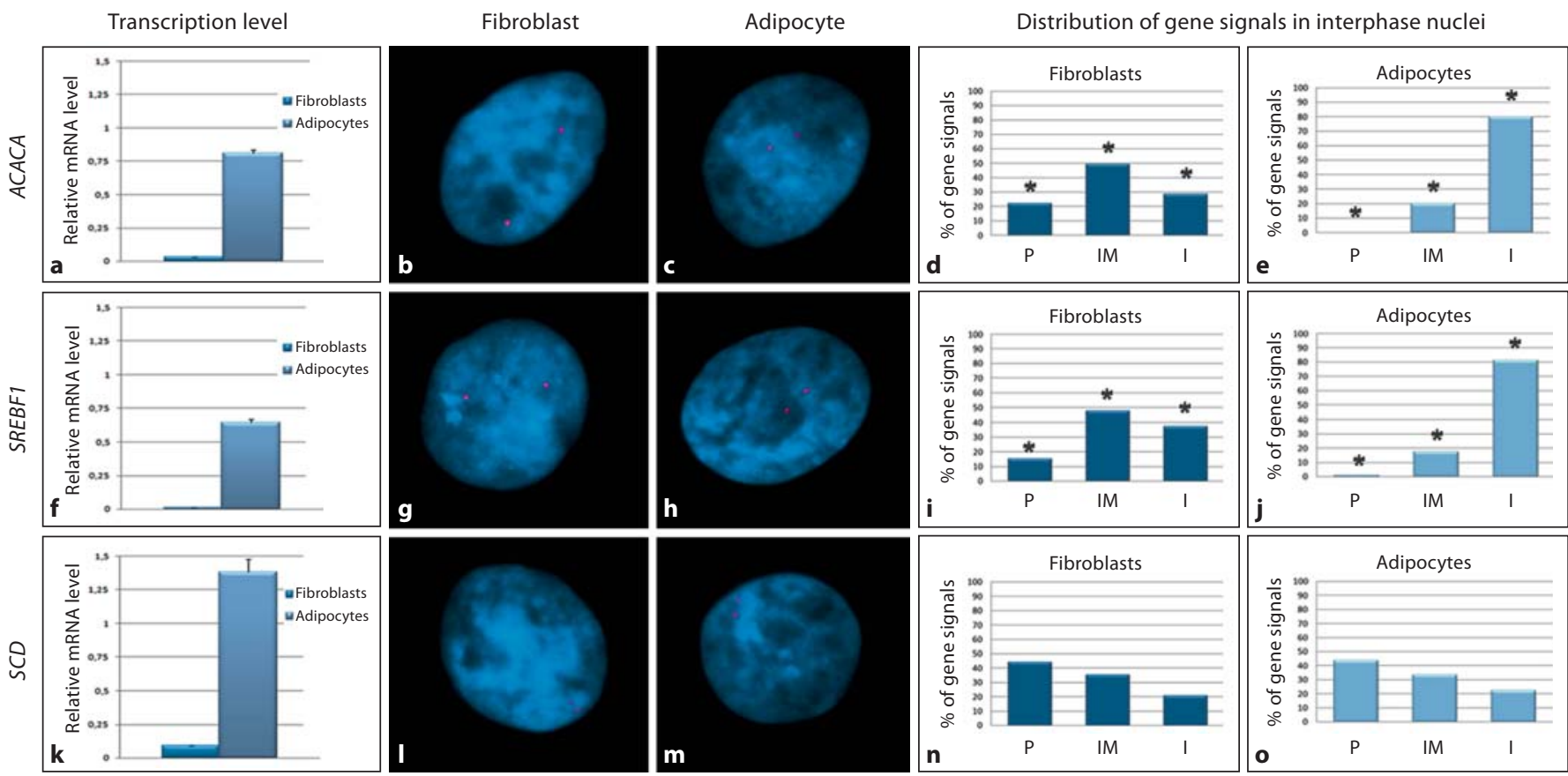

Fig. 2. Representative images of nuclear positioning of the studied genes in interphase nuclei of porcine fibroblasts $(\mathbf{b}, \mathbf{g}, \mathbf{I})$ and adipocytes $(\mathbf{c}, \mathbf{h}, \mathbf{m})$ in relation to their transcriptional status $(\mathbf{a}, \mathbf{f}, \mathbf{k})$. DNA in the nuclei is counterstained with DAPI in blue and gene probes are delineated in red. $\mathbf{d}, \mathbf{e}, \mathbf{i}, \mathbf{j}, \mathbf{n}, \mathbf{o}$ Nuclear distribution $(P$,

peripheral; I, interior; IM, intermediate) of gene signals in interphase nuclei. Statistically significant differences $(p<0.05)$ of the position of the selected genes between fibroblasts and adipocytes were assessed by the non-parametric Mann-Whitney U test and are indicated by asterisks (for details, see online suppl. table 1).

SSC12
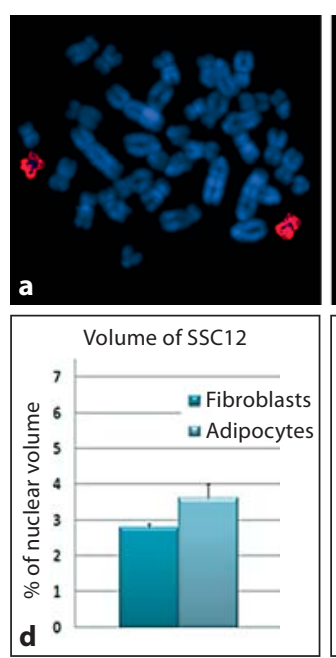

Fig. 3. FISH with painting probes for porcine chromosomes 12 (a-c) and 14 (f-h). a, f Control FISH on metaphase spreads. b, c, $\mathbf{g}, \mathbf{h}$ Representative images of nuclear positioning of SSC12 and SSC14 in interphase nuclei of porcine fibroblasts $(\mathbf{b}, \mathbf{g})$ and adipocytes $(\mathbf{c}, \mathbf{h})$. DNA in the nuclei is counterstained with DAPI in blue and painting probes are delineated in red. $\mathbf{e}, \mathbf{j}$ Comparison of the
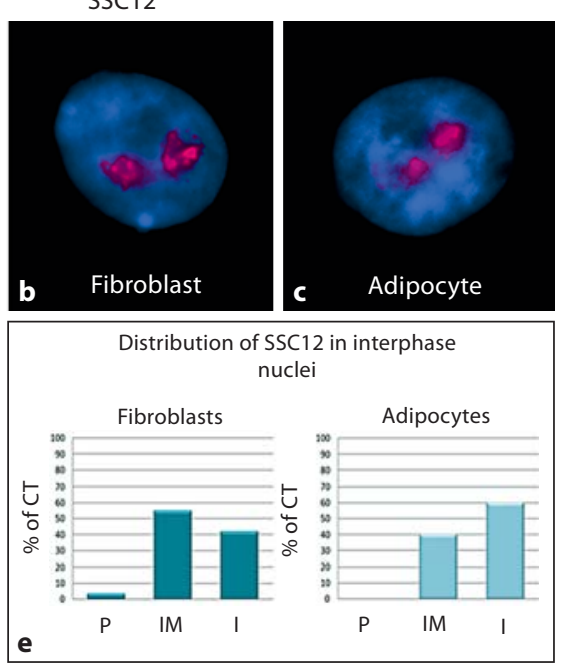
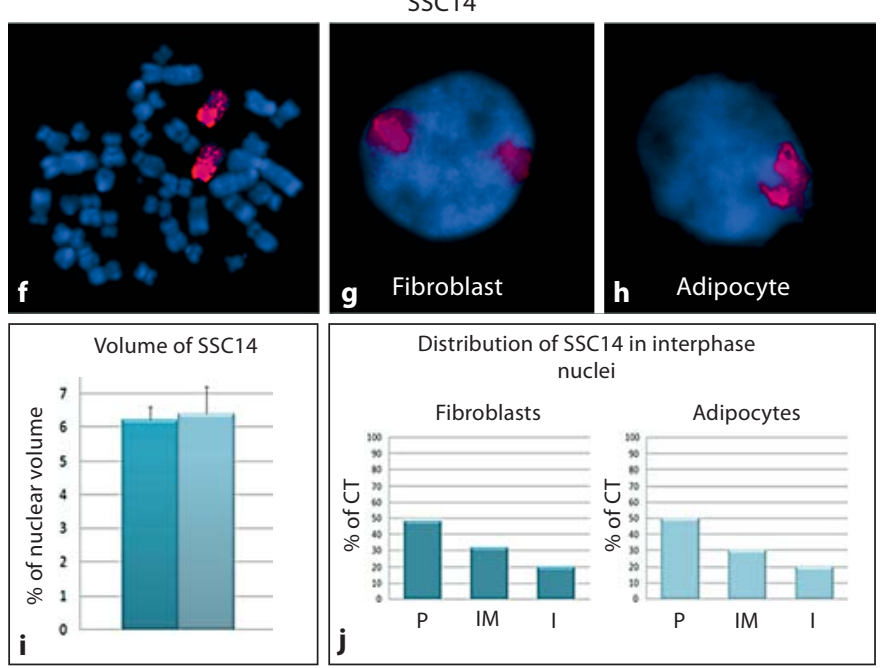

nuclear distribution (P, peripheral; I, interior; IM, intermediate) of chromosome territories in interphase nuclei of porcine fibroblasts and adipocytes. Differences are not significant ( $p>0.05$; for details, see online suppl. table 2). d, i Differences in volume of chromosome territories in interphase nuclei of porcine fibroblasts and adipocytes. 
HSA8, HSA9, HSA10, HSA12, HSA22). However, the relatively large proximal part of the chromosome is homologous to HSA8 and the rather large distal part to HSA10. The position of the HSA 8 chromosome territory is described as intermediate [Boyle et al., 2001] or peripheral [Heride et al., 2010] in human cells, while HSA10 was always found in an intermediate position [Meaburn et al., 2008; Heride et al., 2010; Mehta et al., 2010]. The position of the acrocentric SSC14 may also be determined by possessing a distinct heterochromatin block in the centromere. In a study on the nuclear architecture in porcine neutrophils [Yerle-Bouissou et al., 2009], it was found that centromeres of the chromosomes studied tended to be located at the nuclear border and chromosomes with the same morphology associated preferentially to form chromocenters. Based on the analysis of 2 chromosomes in this study and other porcine chromosomes described in another study [Szczerbal et al., 2009], it seems that the radial arrangement of chromosome territories in pig cells correlates with gene density and in some cases also with chromosome size. Localization of gene-rich porcine chromosome territories in internal regions of the nucleus and gene-poor chromosome territories in the nuclear periphery confirms evolutionary conservation of radial chromatin arrangements in mammalian cells [Foster and Bridger, 2005].

The existence of a strong correlation between gene repositioning and their transcriptional status has been observed only for specific genes, mainly during differentiation and development processes, when genes switch from the silent to the active state [Schöfer and Weipoltshammer, 2008; Joffe et al., 2010]. Recent studies have shown that transcriptional activation of genes by hormone addition was not connected with changes in the nuclear gene positioning [Kocanova et al., 2010; Hakim et al., 2011]. Similarly, variations in expression levels that occurred during bacterial infection did not induce global repositioning of genes in the nuclear space of porcine macro- phages [Solinhac et al., 2011]. Studies concerning the parasite influencing the host interphase genome organization have revealed gene repositioning events, but the behavior of the up-regulated genes was different - one of the studied genes moved to the nuclear interior and the other one moved to the nuclear edge [Knight et al., 2011]. There are also examples of genes having changed their nuclear position without changes in expression [Meaburn and Misteli, 2008]. It seems that relationships between radial positioning of genes and their transcriptional status are more complex and there is no general rule of gene regulation through gene repositioning. Therefore, studies concerning different classes of genes, different cell types and different model organisms are needed to provide a better understanding of functional aspects of spatial positioning of the genome.

Uncovering how the nuclear architecture of adipocyte cells contributes to gene expression has become a subject of special interest in the era of the obesity epidemic. The results of this study demonstrate that (1) chromosome territories and genes are nonrandomly arranged in nuclei of porcine cells, (2) localization of the studied territories is in agreement with the concept of radial chromatin arrangements depending on gene density and chromosome size, and (3) correlation between transcriptional status and nuclear positioning of lipogenic genes in adult porcine cells is observed for some, but not all, genes.

\section{Acknowledgements}

We would like to thank Prof. Malcolm A. Ferguson-Smith and Dr. Patricia O’Brien (Cambridge Resource Centre for Comparative Genomics, Cambridge University, UK) for flow-sorted pig chromosome paints. We also thank Piotr Pawlak (Poznan University of Life Sciences, Poland) for helping with confocal microscopy. This study was financed by the Polish Ministry of Science and Higher Education, grant no. N N311 288936 and the Iuventus Plus grant no. IP2010 040670.

\section{References}

Bolzer A, Kreth G, Solovei I, Koehler D, Saracoglu $\mathrm{K}$, et al: Three-dimensional maps of all chromosomes in human male fibroblast nuclei and prometaphase rosettes. PLoS Biol 3:e157 (2005)

Boyle S, Gilchrist S, Bridger JM, Mahy NL, Ellis JA, Bickmore WA: The spatial organization of human chromosomes within the nuclei of normal and emerin-mutant cells. Hum Mol Genet 10:211-219 (2001).

3D Nuclear Arrangement of Porcine

Genes in Adipocytes and Fibroblasts
Cytogenet Genome Res 2012;136:295-302 
-Fernyhough ME, Vierck JL, Hausman GJ, Mir PS, Okine EK, Dodson MV: Primary adipocyte culture: adipocyte purification methods may lead to a new understanding of adipose tissue growth and development. Cytotechnology 46:163-172 (2004).

- Ferrai C, de Castro IJ, Lavitas L, Chotalia M, Pombo A: Gene positioning. Cold Spring Harb Perspect Biol 2:a000588 (2010).

-Finlan LE, Sproul D, Thomson I, Boyle S, Kerr E, et al: Recruitment to the nuclear periphery can alter expression of genes in human cells. PLoS Genet 4:e1000039 (2008).

Foster HA, Bridger JM: The genome and the nucleus: a marriage made by evolution. Genome organisation and nuclear architecture. Chromosoma 114:212-229 (2005).

-Goetze S, Mateos-Langerak J, Hinco J, Gierman HJ, de Leeuw W, et al: The three-dimensional structure of human interphase chromosomes is related to the transcriptome map. Mol Cell Biol 27:4475-4487 (2007).

- Grasser F, Neusser M, Fiegler H, Thormeyer T, Cremer M, et al: Replication-timing-correlated spatial chromatin arrangements in cancer and in primate interphase nuclei. J Cell Sci 121:1876-1886 (2008).

Gué M, Messaoudi C, Sun JS, Boudier T: Smart 3D-FISH: automation of distance analysis in nuclei of interphase cells by image processing. Cytometry A 67:18-26 (2005).

- Guelen L, Pagie L, Brasset E, Meuleman W, Faza $\mathrm{MB}$, et al: Domain organization of human chromosomes revealed by mapping of nuclear lamina interactions. Nature 453:948-951 (2008).

-Gustavsson I: Standard karyotype of the domestic pig. Committee for the Standardized Karyotype of the Domestic Pig. Hereditas 109:151-157 (1988).

- Hakim O, Sung MH, Voss TC, Splinter E, John S, et al: Diverse gene reprogramming events occur in the same spatial clusters of distal regulatory elements. Genome Res 21:697-706 (2011).

-Hepperger C, Mannes A, Merz J, Peters J, Dietzel $\mathrm{S}$ : Three-dimensional positioning of genes in mouse cell nuclei. Chromosoma 117:535-551 (2008).

-Heride C, Ricoul M, Kiêu K, von Hase J, Guillemot V, et al: Distance between homologous chromosomes results from chromosome positioning constraints. J Cell Sci 123:40634075 (2010).

-Iannuccelli E, Mompart F, Gellin J, LahbibMansais Y, Yerle M, Budier T: NEMO: a tool for analyzing gene and chromosome territory distributions from 3D-FISH experiments. Bioinformatics 26:696-697 (2010).

- Joffe B, Leonhardt H, Solovei I: Differentiation and large scale spatial organization of the genome. Curr Opin Genet Dev 20:562-569 (2010).

- Kim SH, McQueen PG, Lichtman MK, Shevach EM, Parada LA, Misteli T: Spatial genome organization during T-cell differentiation. Cytogenet Genome Res 105:292-301 (2004).

Knight M, Ittiprasert W, Odoemelam EC, Adema CM, Miller A, et al: Non-random organi- zation of the Biomphalaria glabrata genome in interphase Bge cells and the spatial repositioning of activated genes in cells co-cultured with Schistosoma mansoni. Int J Parasitol 41:61-70 (2011).

Kocanova S, Kerr EA, Rafique S, Boyle S, Katz $E$, et al: Activation of estrogen-responsive genes does not require their nuclear co-localization. PLoS Genet 6:e1000922 (2010).

-Kosak ST, Skok JA, Medina KL, Riblet R, Le Beau $M M$, et al: Subnuclear compartmentalization of immunoglobulin loci during lymphocyte development. Science 296:158-162 (2002).

Kuroda M, Tanabe H, Yoshida K, Oikawa K, Saito A, et al: Alteration of chromosome positioning during adipocyte differentiation. J Cell Sci 117:5897-5903 (2004).

- Meaburn KJ, Misteli T: Cell biology: chromosome territories. Nature 445:379-781 (2007).

-Meaburn KJ, Misteli T: Locus-specific and activity-independent gene repositioning during early tumorigenesis. J Cell Biol 180:39-50 (2008).

Meaburn KJ, Newbold RF, Bridger JM: Positioning of human chromosomes in murine cell hybrids according to synteny. Chromosoma 117:579-591 (2008).

Mehta IS, Amira M, Harvey AJ, Bridger JM: Rapid chromosome territory relocation by nuclear motor activity in response to serum removal in primary human fibroblasts. Genome Biol 11:R5 (2010).

-Morey C, Kress C, Bickmore WA: Lack of bystander activation shows that localization exterior to chromosome territories is not sufficient to up-regulate gene expression. Genome Res 19:1184-1194 (2009).

Neusser M, Schubel V, Koch A, Cremer T, Müller S: Evolutionarily conserved, cell type and species-specific higher order chromatin arrangements in interphase nuclei of primates. Chromosoma 116:307-320 (2007).

Osborne CS, Chakalova L, Brown KE, Carter D, Horton A, et al: Active genes dynamically colocalize to shared sites of ongoing transcription. Nat Genet 36:1065-1071 (2004).

- Parada LA, McQueen PG, Misteli T: Tissue-specific spatial organization of genomes. Genome Biol 5:R44 (2004).

Peric-Hupkes D, Meuleman W, Pagie L, Bruggeman SW, Solovei I, et al: Molecular maps of the reorganization of genome-nuclear lamina interactions during differentiation. Mol Cell 38:603-613 (2010).

-Ragoczy T, Bender MA, Telling A, Byron R, Groudine M: The locus control region is required for association of the murine betaglobin locus with engaged transcription factories during erythroid maturation. Genes Dev 20:1447-1457 (2006).

Reddy KL, Zullo JM, Bertolino E, Singh H: Transcriptional repression mediated by repositioning of genes to the nuclear lamina. $\mathrm{Na}-$ ture 452:243-247 (2008).

Ren J, Knorr C, Habermann F, Fries R, Huang LS, Brenig B: Assignment of the porcine stearoyl-CoA desaturase (SCD) gene to
SSC14q27 by fluorescence in situ hybridization and by hybrid panel mapping. Anim Genet 34:471-473 (2003).

-Schöfer C, Weipoltshammer K: Gene dynamics and nuclear architecture during differentiation. Differentiation 76:41-56 (2008)

Solinhac R, Mompart F, Martin P, Robelin D, Pinton P, et al: Transcriptomic and nuclear architecture of immune cells after LPS activation. Chromosoma 120:501-520 (2011).

- Solovei I, Kreysing M, Lanctôt C, Kösem S, Peichl L, et al: Nuclear architecture of rod photoreceptor cells adapts to vision in mammalian evolution. Cell 137:356-368 (2009).

Spurlock ME, Gabler NK: The development of porcine models of obesity and the metabolic syndrome. J Nutr 138:397-402 (2008).

-Szczerbal I, Bridger JM: Association of adipogenic genes with SC-35 domains during porcine adipogenesis. Chromosome Res 18:887895 (2010).

-Szczerbal I, Chmurzynska A: Chromosomal localization of nine porcine genes encoding transcription factors involved in adipogenesis. Cytogenet Genome Res 121:50-54 (2008).

-Szczerbal I, Lin L, Stachowiak M, Chmurzynska $\mathrm{A}$, Mackowski M, et al: Cytogenetic mapping of DGAT1, PPARA, ADIPOR1 and CREB genes in the pig. J Appl Genet 48:73-76 (2007).

Szczerbal I, Foster HA, Bridger JM: The spatial repositioning of adipogenesis genes is correlated with their expression status in a porcine mesenchymal stem cell adipogenesis model system. Chromosoma 118:647-663 (2009).

Takizawa T, Meaburn KJ, Misteli T: The meaning of gene positioning. Cell 135:9-13 (2008a).

- Takizawa T, Gudla PR, Guo L, Lockett S, Misteli T: Allele-specific nuclear positioning of the monoallelically expressed astrocyte marker GFAP. Genes Dev 22:489-498 (2008b).

Tanabe H, Müller S, Neusser M, von Hase J, Calcagno E, et al: Evolutionary conservation of chromosome territory arrangements in cell nuclei from higher primates. Proc Natl Acad Sci USA 99:4424-4429 (2002).

-Volpi EV, Chevret E, Jones T, Vatcheva R, Williamson J, et al: Large-scale chromatin organization of the major histocompatibility complex and other regions of human chromosome 6 and its response to interferon in interphase nuclei. J Cell Sci 113:1565-1576 (2000).

Williams RR, Azuara V, Perry P, Sauer S, Dvorkina $M$, et al: Neural induction promotes largescale chromatin reorganisation of the Mash1 locus. J Cell Sci 119:132-140 (2006).

Xu M, Cook PR: The role of specialized transcription factories in chromosome pairing. Biochem Biophys Acta 1789:2155-2160 (2008).

-Yerle-Bouissou M, Mompart F, Iannuccelli E, Robelin D, Jauneau A, et al: Nuclear architecture of resting and LPS-stimulated porcine neutrophils by 3D FISH. Chromosome Res 17:847-862 (2009). 